\title{
Reseña. María Ospina Pizano, El rompecabezas de la memoria. Literatura, cine y testimonio de comienzos de siglo en Colombia. Madrid/Frankfurt: Iberoamericana/Vervuert, 2019
}

\section{Review. María Ospina Pizano, El rompecabezas de la memoria. Literatura, cine y testimonio de comienzos de siglo en Colombia. Madrid/Frankfurt: Iberoamericana/Vervuert, 2019}

En las últimas décadas Colombia se ha convertido en un hot spot para distintos tipos de públicos atraídos por diferentes motivos y posibilidades. Los jóvenes estadounidenses que eligen Medellín como destino de vacaciones lo hacen porque allí las fiestas son menos caras que en su ciudad de origen y las discotecas tienen horarios más generosos. Los turistas descubren las playas del Océano Atlántico, la enorme biodiversidad y cuanto le hace merecer al país el membrete de mágico. Estos visitantes no se suelen interesar sobremanera por el pasado, ni lejano ni reciente, sino que quieren aprovechar la paz reinante para viajar y disfrutar del presente. Muy distintos son los motivos que atraen a los académicos que están volcando sus esfuerzos investigativos masivamente hacia Colombia no tanto por la 
CATEDRAL TomAda: Revista de crítica literaria latinoamericana / Journal of Latin American Literary Criticism Reseña. María Ospina Pizano, El rompecabezas de la memoria. Literatura, cine y testimonio de comienzos de siglo en Colombia. Madrid/Frankfurt: Iberoamericana/Vervuert, 2019

paz recién conquistada - de la que suelen relativizar el alcance- sino por lo que se ha dado en llamar el "postconflicto": el interés se explica más que todo por la relación estrecha que esta etiqueta implica entre el presente difícil y el pasado reciente del país. Cuánto los politólogos y los sociólogos se enfocan en las negociaciones de paz y las relaciones de poder cambiantes, lo ve cualquier lector que entra en una librería donde a veces se reserva una estantería completa para el tema. Al mismo tiempo se está engrosando rápidamente el corpus de estudios sobre cultura colombiana contemporánea: arte, cine, literatura, música, testimonios, de manera que estamos asistiendo a la configuración intensa y rápida de un campo de estudios culturales colombianos. El tema en sí no es nuevo: ya antes del nuevo milenio se investigaba la cultura colombiana en relación con su contexto de producción político y social. Sin embargo, esos estudios no eran tan numerosos y, vistos desde ahora, parece que preparaban el terreno para el boom al que estamos asistiendo en la actualidad.

El libro de María Ospina Pizano se inscribe en esta tendencia y sus contornos quedan claros desde el subtítulo. Su programa es vasto, pues se propone analizar un amplio corpus de textos literarios, producciones fílmicas y testimonios que se dieron a conocer al público al inicio del nuevo milenio en Colombia. El marco global de sus análisis lo aclara el propio título: interpreta la cultura desde la perspectiva de los estudios de la memoria, abordándola por lo tanto en función de lo que pueda aportar a la reconstrucción de la memoria pública, centrándose en las posibilidades que genera para cuestionar las versiones oficiales de la historia y para contribuir a la catarsis colectiva de la nación. Esto impregna el estudio con un enfoque normativo que, por lo demás, es común en los análisis actuales sobre este tipo de temas pero que aquí se exhibe de manera palpable en algunas comparaciones entre novelas más (Delirio) o menos (El ruido de las cosas al caer) logradas al respecto, entre películas que mejor (El vuelco del cangrejo, La sirga) o peor (Los colores de la montaña, Jardín de amapolas) cumplen con el requisito de hacer memoria. 
Se le concede el honor de abrir el volumen al gran iconoclasta de Colombia, Fernando Vallejo, con lo cual María Ospina reconoce su relevancia en los debates culturales y políticos, admitiendo al mismo tiempo y de forma implícita que algunos de los diagnósticos más relevantes sobre la Colombia contemporánea han llegado desde fuera, en este caso, desde la Ciudad de México, lugar de residencia de Vallejo hasta hace poco. Sin embargo, ya que Ospina estudia los textos y las películas desde una perspectiva inmanente, no entra en este tipo de consideraciones que más bien son propias de la sociología de la literatura o de los intelectuales. Que el punto de partida sea La virgen de los sicarios sorprende un poco, no tanto por su relevancia ni mucho menos por la calidad de la escritura, sino por su fecha de publicación en 1994, lo cual sitúa esta novela en principio fuera del corpus. Pero la elección se justifica porque su objetivo consiste en cotejarla con la biografía de Rufino José Cuervo que Vallejo publicó en 2012. Se trata de una comparación original que parte del hecho de que también el autoficcional Fernando de La virgen de los sicarios es un gramático y que se justifica asimismo porque la novela incluye una importante cantidad de reflexiones sobre la vida de la lengua.

El libro de María Ospina pone de relieve la riqueza de estas reflexiones y también sus numerosas contradicciones, dejando claro así cómo a Vallejo le gusta sembrar la duda, confundir y provocar, cómo hace oscilar al lector entre leerlo en clave cínica o irónica. Al respecto, la crítica trae a colación una pregunta de Jean Franco que da cuenta de esta duda: "As a letrado, he [Fernando] is 'our' ally, 'Mon semblable, mon frère'. The question is whether he is deliberately forcing us to face the 'fascist within' or whether he expects our complicity". Ospina subraya que Franco presenta las dos reacciones del lector como excluyentes: o el lector se hace cómplice de Fernando, o descubre gracias a él su propio fascismo. Por mi parte creo que también es legítimo razonar que Fernando Vallejo espera que seamos sus cómplices al descubrir la no fiabilidad del discurso de su narrador y al hacer visible la corresponsabilidad de este en la violencia. Sea como fuese, la conclusión del análisis acerca de cómo el maestro contempla la realidad del idioma revela la complejidad del tema y la sutileza de la argumentación elaborada por la autora: "en 
CATEDRAL TomAda: Revista de crítica literaria latinoamericana / Journal of Latin American Literary Criticism Reseña. María Ospina Pizano, El rompecabezas de la memoria. Literatura, cine y testimonio de comienzos de siglo en Colombia. Madrid/Frankfurt: Iberoamericana/Vervuert, 2019

una clásica movida dialéctica vallejiana, la crítica al ímpetu normativo de la gramática y a la fantasía de fijar un idioma muy amplio y cambiante no implica un llamado al desmantelamiento radical de todos los códigos del uso de la lengua o a la celebración de la arbitrariedad de los signos. Más bien, podríamos leer en sus constantes lecciones sobre el uso adecuado de reglas gramaticales generales, con las que el autor se convierte en maestro (y defiende su rol), una defensa de un mínimo de códigos y reglas de juego compartidas que provean los nexos y los vínculos que posibilitan el contrato social" (83).

El segundo capítulo se centra en una serie de novelas cuyos protagonistas buscan la verdad de lo que pasó en el pasado reciente y que sufren psíquicamente por estos acontecimientos. Entre ellas, se analizan con mayor ahínco Delirio, de Laura Restrepo y Los ejércitos, de Evelio Rosero, dos novelas que han gozado de una amplia atención crítica y que, aquí, se enfocan especialmente en función del binomio víctimas/victimarios y de criterios genérico-sexuales. Según la autora, la novela de Rosero merece la atención que ha suscitado porque se centra en las víctimas y porque contesta la imagen común de la víctima sufriente y paralizada por el dolor. Esta última idea se repite en el libro, de que la imaginación más estereotipada en Colombia establece una relación estrecha entre victimización y parálisis o abyección. Sin embargo, ya que casi todo el corpus estudiado aquí, independientemente del género discursivo, invalida esta asociación, habría sido interesante saber a qué tipo de discurso común María Ospina se refiere. De la misma manera habría sido útil que se delineara mejor ese otro discurso (en caso de que se puede hablar de uno solo) contra el cual la autora posiciona con cierta constancia los textos y los filmes que analiza. Se trata de "los medios", "el discurso estatal", "oficial”, "público" o "de élites" que, aparte de presentar a las víctimas como abyectas o paralizadas, asegura que el conflicto ha terminado o que nunca ha habido tal. La investigación presupone así una especie de discurso homogéneo e indistinto, cuyas características precisas no se explicitan pero que se presenta como el fondo contra el cual la producción cultural analizada se perfila de forma positiva. 
El análisis de Los ejércitos se centra en una de estas víctimas, el personaje de Ismael Pasos cuyo delirio alude al trauma que sufre y que lo convierte en un típico sobreviviente, un tema central en la novelística colombiana de la época estudiada. En el presente libro el personaje es abordado a partir de una serie de estudios teóricos importantes sobre duelo, memoria y modos testimoniales que también sirven para enmarcar los testimonios analizados en el capítulo final. En realidad, el personaje de Ismael hubiera podido ser analizado también críticamente en función de criterios de género, sobre todo porque la lectura de Delirio, que sigue, se hace desde dicha perspectiva. La idea central en la lectura que hace Ospina de la novela de Restrepo es que "reflexiona sobre el proceso de enfrentar las pérdidas para articularlas a nivel colectivo y, en el proceso, cuestionar configuraciones sociales y genérico-sexuales que determinan la historia nacional" (110). Por lo tanto, Delirio se interpreta especialmente a partir de preguntas relacionadas con las maneras en que la familia burguesa y su jerarquía patriarcal influyen en sus miembros femeninos. La conclusión es que el capitalismo presupone un "orden identitario masculino que necesita de la violencia (violencia de género, homofobia) para constituirse" (132).

Son ideas potentes y ricamente elaboradas que dan cuenta de la sofisticación y los contenidos críticos de Delirio y que no solo sirven para pensar la reciente historia de Colombia sino de occidente en general. El fino análisis propuesto por María Ospina aún se podría completar tomando en consideración el papel desempeñado por la madre de la protagonista Agustina, Eugenia, ya que aparece como una de las guardianas más relevantes del statu quo. A través de este personaje, Laura Restrepo apunta a la complicidad de muchas mujeres cuando se trata de defender los roles de género más tradicionales dentro de lo que Carole Pateman ha llamado el "contrato sexual", una complicidad a la que alude buena parte de la literatura colombiana, aunque Restrepo lo hace con una sutileza especial. Que esta autora no ocupe una posición más destacada en el campo literario, posiblemente también se debe a una cuestión de género. 
CATEDRAL TomAdA: Revista de crítica literaria latinoamericana / Journal of Latin American Literary Criticism Reseña. María Ospina Pizano, El rompecabezas de la memoria. Literatura, cine y testimonio de comienzos de siglo en Colombia. Madrid/Frankfurt: Iberoamericana/Vervuert, 2019

Asimismo, son interesantes las ideas de Ospina en torno a la violencia homofóbica que surge en relatos que evidencian preocupación por "el resquebrajamiento de las masculinidades heteronormativas" (135). Es lo que pasa efectivamente en novelas como Rosario Tijeras y El ruido de las cosas al caer, que construyen personajes masculinos ansiosos por retener su "masculinidad compulsiva". Por nuestra parte, nos llama la atención la gran cantidad de personajes homosexuales en la narrativa colombiana reciente que, por lo tanto, merecerían ser analizados en su conjunto. Así, en La virgen de los sicarios tanto el narrador como sus amantes sicarios son homosexuales de manera que en esta novela se instaura lo que Mary Louise Pratt ha llamado un "nuevo orden social monosexual" que amenaza la continuidad de la vida y que, en un texto con un claro mensaje antihumanista, celebra su extinción. Como dijo Héctor Hoyos, da un sentido literal a la idea de criticar la reproducción del orden social. El padre del narrador en El olvido que seremos se sentía atraído hacia los adolescentes; Raquel y Juana en Cartas cruzadas, de Darío Jaramillo Agudelo, y Antonio y Jon en La Oculta, de Héctor Abad Faciolince, tienen una relación homosexual; Mauro, el capo de El divino es homosexual, y algunos compañeros suyos parecen compartir su preferencia por los hombres; el comandante Paraíso en otra novela, homónima, de Gustavo Álvarez Gardeazábal tiene relaciones con hombres y mujeres. Se trata de personajes que desempeñan papeles muy distintos, dos de ellos no tienen relaciones algunas con el mundo de la delincuencia, dos son amigas de un mafioso, hay una víctima del sicariato, varios sicarios, un autor intelectual de crímenes, y algunos capos.

No obstante, todos ellos contribuyen a dar visibilidad a un grupo que el discurso colombiano tradicional hasta hace poco silenciaba porque la distribución de lo sensible (Jacques Rancière) no le previó ningún espacio propio que le correspondiera. Si el padre del Bichi en Delirio le da palizas, es para transformarlo en un verdadero hombre que pueda ocupar el lugar previsto para él dentro de la sociedad común y para que pueda continuar el linaje. Y si bien en las otras novelas la homosexualidad es en parte aceptada por el medio en el que funcionan los personajes, la presencia de homosexuales en todas ellas apunta a un tabú en la 
sociedad y parece dar cuenta de un deseo de sus autores de que se renegocie el reparto de lo sensible para que quepan. En otras palabras, como los personajes en Delirio, los personajes homosexuales en las novelas sobre narcos y sicarios señalan la necesidad de flexibilizar la sociedad. Su presencia confirma lo dicho por Bernat Castany Prado de que, entre las estrategias aptas para desesencializar la nación, destaca la construcción de personajes que problematizan y ponen en tela de juicio las definiciones nacionalistas más rancias.

En realidad, y para continuar hilando nuestras reflexiones a partir de aquellas propuestas por María Ospina, pareciera que, cuando el homosexual se relaciona con el narcotráfico, en la literatura esta dimensión "posnacional" queda reforzada. A primera vista son categorías que no tienen nada que ver una con otra. Los narcos y sicarios remiten a una profesión y los homosexuales a una cuestión de género. Los primeros trabajan en la ilegalidad o incluso en la criminalidad, contrariamente a los segundos que no vehiculan ninguna connotación al respecto. Por estas razones no se pueden confundir o identificar. Sin embargo, no parece ser casual que algunos escritores opten por crear mafiosos homosexuales. Tanto los unos como los otros se posicionan fuera de la sociedad común y tópica y a los dos esta sociedad los quiere relegar fuera de lo visible. Ambos representan un desvío frente a las normas y lo que se considera comúnmente como la normalidad. Ambos son grupos reales en la sociedad, implantados sólidamente en ella y a veces aceptados en la intimidad de la vida privada, pero rechazados cuando se manifiestan en la vida pública y mantenidos alejados de los lugares de socialización (en Delirio es claramente el caso con los mafiosos). En este sentido creo que, en varios casos, en la figura del narco homosexual intensifica la demanda de parte de los autores por disminuir el carácter policial de la sociedad colombiana o renegociar la visibilidad a estos grupos.

En el tercer capítulo del libro se analiza una serie de filmes recientes cuyos protagonistas son niños o adolescentes y cuyo escenario es -al menos en parterural. De esta forma ilustran lo que la autora llama el "giro rural" en el cine colombiano, giro que ha estudiado en un capítulo de otro importante libro de 
CATEDRAL TomAda: Revista de crítica literaria latinoamericana / Journal of Latin American Literary Criticism Reseña. María Ospina Pizano, El rompecabezas de la memoria. Literatura, cine y testimonio de comienzos de siglo en Colombia. Madrid/Frankfurt: Iberoamericana/Vervuert, 2019

estudios culturales colombianos publicado en fechas recientes, Territories of Conflict. Traversing Colombia Trough Cultural Studies (2017, Andrea Fanta Castro, Alejandro Herrero-Olaizola y Chloe Rutter-Jensen eds.). La interrogación de la que parte para acercarse a las películas es la siguiente: “Cómo expanden categorías como memoria, testigo, víctima, ciudadanía y postconflicto a partir de una consideración de la dimensión de la minoría de edad?" (153). Este cuestionamiento ético y político se aplica principalmente a las películas Jardín de amapolas, Los colores de la montaña, El vuelco del cangrejo, La Playa D.C., La sirga y Alias María. Al comentarlas, la autora incluye criterios étnicos (sobre todo relativos a las comunidades afrocolombianas) y económicos (clases trabajadoras). Su enfoque la lleva a constatar la ausencia del Estado-nación en las películas, una constatación que se podría extender sin problemas a la literatura, pues en pocas novelas colombianas aparecen fuerzas de autoridad que en principio deberían proteger a los ciudadanos. Otra conclusión a la que llega María Ospina que podría transponerse al corpus novelístico es que los finales de estas películas, aunque abiertos, son poco optimistas. En cuanto a muchas novelas que hablan de violencias recientes o del postconflicto, parece que confían en la posibilidad de que los traumas individuales se curen, pero el hecho de que las historias que cuentan no se refieren a ninguna transformación política, social o moral significativa, hace que esta mejoría parezca poco sólida. Es como si, de esta manera, apuntaran oblicuamente a lo lábiles y lo limitados que son los resultados de la reciente y creciente pacificación del país.

En este capítulo sobre cine se mantiene el enfoque normativo de que es importante que las producciones culturales muestren víctimas que no sean silenciosas o inconscientes de lo que pasa a su alrededor. Así, el filme Los colores de la montaña es objeto de la crítica de la autora porque no alcanza a "pensar en la víctima como testigo que busca comprender o resistir activamente $\mathrm{y}$, en muchos casos, cuestionar el conflicto que presencia” (162). El presupuesto de María Ospina es que incluso los menores de edad entienden la guerra y se apropian un espacio para actuar; asume que su experiencia del mundo violento es distinta a la del adulto, 
pero no por esto inocente. Los cineastas que no cumplen con la obligación de mostrar esto, no examinan a fondo la experiencia infantil causada por la guerra. Aquí surge una dificultad, sobre todo en vista de las sensibilidades contemporáneas relativas a cuestiones de representación. Así, en el último capítulo del libro (213) se trae a colación a Doris Sommer cuando alerta contra la idea de que conocemos al otro lo suficientemente bien como para hablar por él. Esta sospecha puede transferirse a los narradores y focalizadores infantiles: ¿Cómo exigir de los cineastas o escritores que se apropien de las voces y las miradas de niños, si, siendo adultos, el acceso que tienen a ellas es inevitablemente mediado? El hecho de elegir no simular estos puntos de vista y lugares de enunciación ¿no podría verse como un indicio de que el cineasta tiene conciencia de los límites inherentes a la representación mediada y de que no quiere traspasarlos?

El volumen se cierra con un bonito análisis de varios relatos epistolares que más de 5300 colombianos de todas partes del país, de todas las edades, han escrito en el marco de una iniciativa liderada por la Biblioteca Luis Ángel Arango en 2007. El proyecto, llamado Cartas de la Persistencia, buscó estimular la redacción de misivas y activar lecturas más allá de los cintos amurallados de la ciudad letrada. Que lo lograra, lo ilustra el hecho de que tantos colombianos mandaron una carta a uno o varios destinatarios. Ya que no pasan por ninguna fuente de mediación -al menos no tan visiblemente- constituyen los testimonios más directos del corpus estudiado en relación con lo que los colombianos han sufrido en los últimos años. Quizás sea por esto que logran despertar tanta emoción.

El DRAE propone tres definiciones de la palabra 'rompecabezas'. La primera, un tipo de armas, no viene a cuenta aquí. La segunda dice: "Juego que consiste en componer determinada figura combinando cierto número de pedazos de madera o cartón, en cada uno de los cuales hay una parte de la figura" y la tercera es un "Problema o acertijo de difícil solución". Ambas acepciones que apuntan respectivamente a la posibilidad y a la dificultad de encontrar una salida y llegar a un desenlace, se adecuan al libro, sobre todo tomadas juntas. María Ospina arma una figura compleja de la cultura colombiana contemporánea a partir de un 
CATEDRAL TomAda: Revista de crítica literaria latinoamericana / Journal of Latin American Literary Criticism Reseña. María Ospina Pizano, El rompecabezas de la memoria. Literatura, cine y testimonio de comienzos de siglo en Colombia. Madrid/Frankfurt: Iberoamericana/Vervuert, 2019

conjunto importante de pedazos. Esta figura sin embargo no supone ninguna solución, y tampoco nadie se la pide, porque la cultura, más que proponer soluciones, suscita preguntas.

(cc) EY New articles in this journal are licensed under a Creative Commons Attribution 4.0 United States License.

ULLS D-Serle This site is published by the University Library System, University of Pittsburgh as part of its D-Scribe Digital Publishing Program and is cosponsored by the University of Pittsburgh Press. 